\title{
Impact of Self-Efficacy Beliefs on Short- and Long-Term Academic Improvements for Underperforming Medical Students
}

\author{
Bunmi S. Malau-Aduli*, Wendy Page, Nick Cooling, Richard Turner \\ School of Medicine, University of Tasmania, Hobart, Australia \\ *Corresponding author: bunmi.malauaduli@utas.edu.au
}

Received May 26, 2013; Revised June 02, 2013; Accepted June 06, 2013

\begin{abstract}
This study investigated the effectiveness of an innovative remediation program, based on promoting self-efficacy, a construct of self-regulation theory, which was developed to provide sustainable improvements in academic and clinical performance of underperforming medical students. Eighteen medical (eight $4^{\text {th }}$ and ten $5^{\text {th }}$ year) students participated in the remediation program. Interventions were multi-faceted and composed of a wide range of group activities. The efficacy of the intervention was evaluated using mixed-method approach consisting of interviews, questionnaire and quantitative analysis of OSCE outcomes (pre and post intervention). The in-depth interviews were used to explore the short- and long-term causal effects of the remediation program on improved performance. Students demonstrated significant improvements across 3 of the 5 domains measured in OSCE performance (management, diagnosis and communication). There was a $44 \%$ improvement in number of stations passed by participants post-remediation (95\% CI $=-52.25$ to $-35.64 ; \mathrm{r}=0.82)$. Large effect sizes were obtained, indicating the substantive significance of the results. Self-efficacy beliefs were markedly increased post-intervention with the total score increasing from $33.52(\mathrm{SD}=4.9)$ points pre-remediation to 45.71 (SD=5.1) points postremediation (95\% CI $=-14.52$ to $-9.83 ; \mathrm{p}<0.001 ; \mathrm{r}=0.77)$. Subsequent qualitative data suggested that beyond summative exam results, gains were translated to the clinical context with enhanced confidence and self-belief, enabling perceived improved performance in the workplace. Multi-dimensional, group orientated remediation, which emphasises self-efficacy beliefs, may enhance outcomes for students in both high stakes assessment and in the clinical context, thus allowing translational and longitudinal benefits.
\end{abstract}

Keywords: self-efficacy, underperforming medical students, effective intervention, support, objective structured clinical examination (OSCE)

\section{Introduction}

The imperative to improve learning outcomes for medical students goes beyond moral and ethical constructs for educators, but also potentially impacts on the wider community in relation to safety and quality in health care. Studies have shown that up to $15 \%$ of students underperform during medical school [1], particularly in their clinical performance assessments $[2,3]$. This group of students fail to meet the expected competence standards for cognitive and affective skills and they require additional support, sometimes called 'remediation'. Remediation processes usually involve diagnosis, intervention activities and re-testing [4]. Medical schools vary in the design, intensity and scope of remediation offered to students who underperform in their academic and clinical assessments [2,5,6,7,8].

Despite the relatively high prevalence of underperformance and the desire of most medical schools to deliver some form of intervention program, recent reviews reveal that there are few published descriptions of remediation programs and minimal evaluations of the effectiveness of these interventions [9,10]. Researchers have also highlighted the need for further studies focusing on the enduring effectiveness of remediation intervention plans in the long term [11,12]. Future research needs to target more rigorous approaches to developing and evaluating remediation interventions, and include the use of theory to conceptualise the intervention [10].

While academic failure may have focused, in the past, on lack of knowledge, contemporary studies have demonstrated that most underperforming medical students have difficulties in multiple domains with psychological factors being highly relevant $[5,13,14]$. Extensive research in educational psychology has revealed that self-efficacy (SE) is a major psychological factor that influences students' learning through cognitive as well as motivational mechanisms $[15,16]$. The ability to succeed and display adequate effort when challenged by a task can be grossly undermined by low SE beliefs [17]. Various studies have demonstrated the translation of positive effects on SE to desirable practice patterns in clinical training programs $[18,19,20]$. However, SE has not been extensively studied in the context of poor academic performance in medical students. 


\subsection{Conceptual Framework}

SE is an important psychological and motivational construct within the self-regulatory learning theory. Based on the concept of dialectical constructivism, self-regulated learning theory requires that students are active in their learning processes [21]. Studies have shown links between self-regulation and improved academic outcomes [22,23]. According to Zimmerman [24], self-regulated learning is defined as "those self-governing processes and self-beliefs that facilitate the student's transformation of mental abilities into school-performance abilities" (p.166). Strategic planning, which involves effective monitoring, regulated learning and problem solving processes is a vital component of self-regulated learning and it is critical for successful performance [25].

In his seminal work on SE, Bandura [15] defined selfefficacy beliefs as "people's judgments of their capabilities to organise and execute courses of action required to attain designated types of performances" (p.391). Previous studies on SE have emphasised its central role in all the three phases of self-regulation, namely forethought, performance and self-evaluation based on reflection [26,27]. SE predicts cognitive and selfregulatory processes using a triadic reciprocal causation model in which behaviour, cognition and the environment all influence each other in a dynamic fashion [15,28]. SE has particular influence on an individual's choices, goal commitment and persistence on a task $[15,29]$ and as such it changes as a result of learning, experience and feedback [30]. SE highlights the role of 'self-referent thought' in guiding human action and change. According to this construct, behaviour changes achieved through diverse methods such as guided exposure, modelling, persuasion and anxiety reduction are in part, the result of creating or strengthening one's belief in one's ability to successfully perform a given task [15].

It is claimed that SE is an important precursor for releasing the true potential of learning in students [31]. The benefit of SE has been demonstrated in the OSCE setting with $2^{\text {nd }}$ year medical students [32]. Conversely a negative OSCE experience reduces student confidence in subsequent clinical performance [33].

In this study, we investigated the effectiveness of a remediation program which was developed based on socio-cognitive SE beliefs to improve academic and clinical performance of underperforming medical students in a 5-year undergraduate medical course at an Australian Medical School. The previous remediation program offered by the School involved each repeating or re-sit student being attached to a clinical mentor on request, and OSCE practice sessions in collaboration with other remediation students and a medical education officer. This method was not only inconsistent in improving students' OSCE performance, but had limited benefit in improving longer term attributes of self-confidence and ability to learn from mistakes.

We hypothesised that if underperforming students are provided with intervention strategies that motivate them to self-reflect and strengthen their SE beliefs; they will be more successful in their summative clinical assessments (OSCE) and develop consulting skills and professional attributes that are sustained into their clinical careers.
The study was designed to answer the following research questions:

1. Would an intervention aimed at building SE and consisting of multiple, cost-effective, group learning activities improve subsequent OSCE performance and perceived clinical confidence in underperforming medical students?

2. What interventions are perceived to be most useful?

3. What are the perceived long-term benefits of the intervention program on the clinical performance of underperforming medical students?

\section{Methods}

\subsection{Participants}

At the beginning of the 2011 academic year, all $4^{\text {th }}$ and $5^{\text {th }}$ year medical students who sat supplementary examinations in the previous year or who were repeating the year, as well as some students with demonstrated difficulty in workplace assessments and referred by clinical supervisors were invited to participate in the new remediation program. All the invited medical students, comprising eight $4^{\text {th }}$ and ten $5^{\text {th }}$ year students (a total of 18 participants) volunteered to participate in the remediation program. This study received ethics approval from the Tasmanian Social Science Human Research Ethics Committee.

\subsection{New Remediation Program}

A multi-dimensional ten-week support program (Additional Leaning Support Opportunity - ALSO) was initiated, based on individual assessment, but offered primarily as a group learning experience. In addition, individual counselling was offered to all participants to provide psychological support. Participants voluntarily attended all sessions. This new program was developed based on the framework of SE beliefs and consisted of the following elements:

\subsubsection{Presentation Skills}

The participants were given intensive (one and a half to two hours per week) workshops on listening and speaking skills with a Professor of Theatre Arts. Group activities (six participants per group) included action-reaction exercises, breathing and articulation work on voice, as well as walk-talk situations to enhance individual presence, confidence and anxiety management. Work on voice also included shifting and sliding vocals to accompany thought and to bring interest and engagement to the listener. Individual presentations with critical analysis of performance were offered in a supportive, but challenging learning environment.

\subsubsection{OSCE Practice with Clinical Teachers}

We offered the students a 4-station mock OSCE. Students were initially assessed by clinicians, and then videotapes of the stations were used to provide individual and group feedback. Thematic feedback on how each student performed in relation to assessed competency domains was also provided. Each student was given a copy of their own OSCE video to watch and later engaged 
in a discussion with the coordinators (including the Professor of Theatre Arts) about his or her performance.

\subsubsection{OSCE Practice with other Students}

All the participants were also invited to serve as mock examiners during a $3^{\text {rd }}$ year mock OSCE session. They were able to assess the performance of their junior colleagues and provide them with verbal feedback. Individual peer learning sessions (one session per week) with student mentors were also initiated.

\subsubsection{Bedside Teaching}

This consisted of twice weekly targeted bedside tutorials in which small groups (between three to six participants per group) were able to gain high quality, context specific teaching in the clinical setting with senior registrars.

\subsection{Evaluation of the New Remediation Program}

The ALSO intervention program was implemented in 2011. We evaluated the short- and long-term benefits of the program for the participants over a two-year period (2011-2012), using a mixed methods approach, incorporating both qualitative and quantitative data collection and analysis for triangulation of data [34].

\subsubsection{Data Collection}

To answer the first research question, we collated and analysed participants' summative OSCE results (pre- and post-intervention program) to compare pass rate and performance scores in relation to assessed clinical competencies. To answer the second and third research questions, we administered a questionnaire and conducted individual interviews.

A retrospective pre-post self-assessment and program evaluation questionnaire was administered immediately after the completion of the program. The retrospective pre-post questionnaire approach was modelled after the studies reported by Skeff et al and Hewson et al [35,36]. In comparison to traditional pre-post self-assessment, the retrospective approach has been reported to provide a more sensitive and valid measure of faculty development evaluations [35]. The questionnaire included four sections. Section A focused on the demographics of the participants. Section B explored the participants' perception of their SE beliefs in relation to their self-esteem, self-confidence, knowledge, communication skills, stress management and diagnostic skills before and after the remediation program. This was measured using a 14-item 5-point Likert scale. The items were tailored to correspond directly to the targeted performances [17]. Section C required the participants to rate the worth of the different intervention activities on a 5-point scale, where 1 is not at all worthwhile and 5 is extremely worthwhile. In section D, we used open-ended questions to elicit the most and least useful parts of the program as well as areas for improvement.

In-depth interviews were conducted at the end of the 2011 and 2012 academic years to explore the short- and long-term causal effects of the remediation program on improved performance. Six participants, comprising three males and three females; four international and two domestic students, volunteered to participate in the interview sessions. Four of them were in $5^{\text {th }}$ year in 2011 and they were interns in 2012, while the remaining two participants were $4^{\text {th }}$ year students in 2011 and $5^{\text {th }}$ year students in 2012. The interviews took place in informal classroom settings, lasted about 30 minutes each, were audio recorded and transcribed verbatim. The interviews were conducted by one of the authors.

\subsubsection{Data Analysis}

We computed descriptive statistics for participant characteristics and comparisons between pre- and postintervention OSCE performance scores and pass rates related to assessed clinical competencies. Prior to analysis, the survey items were screened for accuracy and assessed for normality. Upon confirmation of normality of distribution of scale items, we compared the means scores using a paired t-test. We tested for group differences in relation to preferred remediation activities, using the independent samples t-test. Significant levels were set at 0.05 and effect sizes were calculated to determine the magnitude of statistically significant relationships. We analysed data using SPSS version 19.0 (SPSS Inc., Chicago, Illinois) [37].

Data from the open-ended survey items and the interviews were collated and independently analysed by the investigators, using thematic analysis as described by Braun and Clarke [38]. The data were initially subjected to inductive, bottom-up analysis [39], with comments coded and grouped into key terms and phrases of related meaning. These phrases were then refined and organised to derive themes using deductive, top-down analysis [40], for comparison of new findings with pre-developed code lists from the literature. All the investigators convened to discuss their coding and the themes identified. Through discussions, they reached consensus on a series of main themes into which all significant findings fitted. Illustrative quotes were reported verbatim to support the discussion.

\section{Results}

\subsection{Quantitative}

Research Question 1: Would an intervention aimed at building SE and consisting of multiple, cost effective, group learning activities improve subsequent OSCE performance and perceived clinical confidence in underperforming medical students?

Of the 18 students involved in the remediation program, 17 (94\%) completed the questionnaire. The group comprised of eight $4^{\text {th }}$ year and nine $5^{\text {th }}$ year medical students. Fifty nine percent (59\%) of the participants were males, $41 \%$ were females. All the participants were in the $21-30$ years age group and $77 \%$ were international students.

Table 1 provides student performance data on all assessed measures in the OSCE before and after the remediation program. Performance on all measures improved after the remediation program with statistically significant improvements on management plan (MP), diagnostic skills (DS), communication skills (CS) and number of stations passed (NSP). The students' post- 
remediation scores were $59.28 \%, 66.78 \%$ and $71.22 \%$ for MP, DS and CS respectively. There was a 44\% improvement in number of stations passed by participants post-remediation (95\% CI $=-52.25$ to $-35.64 ; \mathrm{r}=0.82$ ). Large effect sizes were obtained, indicating the substantive significance of the results. Improvements in history taking skills (HTS) and examination skills (ES) were not significant. As shown in Figure 1, comparison of scores on assessed competencies revealed that all the participants had difficulty with MP and DS pre- remediation irrespective of their year of study. In contrast, all participants performed well in HTS and ES both preand post-remediation. The international students were deficient in CS pre-remediation while the domestic students were proficient in CS both pre and postremediation (data not shown). All 18 participants in the remediation program were successful in their 2011 end of year summative OSCE assessments. In 2012, the participants in their $5^{\text {th }}$ year (eight of them) passed all their examinations without any support/intervention.

Table 1. Comparison of student performance in clinical exams (OSCE) pre and post remediation program (n=18)

\begin{tabular}{|c|c|c|c|c|c|c|}
\hline \multirow[b]{2}{*}{ Performance measure } & \multirow[b]{2}{*}{$\begin{array}{l}\text { Pre-remediation } \\
\text { program (SD) }\end{array}$} & \multirow[b]{2}{*}{$\begin{array}{l}\text { Post-remediation } \\
\text { program (SD) }\end{array}$} & \multicolumn{2}{|c|}{ 95\% Confidence Interval (CI) } & \multirow[b]{2}{*}{ Mean Difference } & \multirow[b]{2}{*}{$\begin{array}{c}\text { Effect Size } \\
\text { (r) }\end{array}$} \\
\hline & & & Lower & Upper & & \\
\hline Management Plan & $47.56(12.05)$ & $59.28(9.82)$ & -19.76 & -3.69 & $-11.72^{\dagger}$ & 0.47 \\
\hline Diagnostic Skills & $46.89(17.46)$ & $66.78(11.12)$ & -29.43 & -10.35 & $-19.88^{\ddagger}$ & 0.56 \\
\hline History Taking Skills & $68.61(13.12)$ & $69.56(9.04)$ & -6.58 & 4.69 & $-0.94^{\mathrm{NS}}$ & 0.04 \\
\hline Communication Skills & $60.61(15.99)$ & $71.22(6.16)$ & -18.51 & -2.71 & $-10.61^{\dagger}$ & 0.40 \\
\hline Examination Skills & $67.00(14.15)$ & $71.22(9.48)$ & -12.71 & 4.27 & $-4.22^{\mathrm{NS}}$ & 0.17 \\
\hline No of Stations Passed (\%) & $44.72(15.64)$ & $88.67(15.19)$ & -52.25 & -35.25 & $-43.94^{\ddagger}$ & 0.82 \\
\hline
\end{tabular}

$\dagger \mathrm{P}<0.01$

$\neq \mathrm{P}<0.001$

\section{NS Not Significant}

Initial screening of the 14 items on the SE scale $(\alpha=$ 0.73) revealed three outliers and these items were removed from the scale. Cronbach's alpha without the outliers was 0.83. Using paired t-test, evaluation of student responses to the 5-point Likert scale survey questions revealed statistically significant increases in their perceived SE post-remediation in comparison to preremediation. As shown in Table 2, the total score increased from $33.52(\mathrm{SD}=4.9)$ points pre-remediation to $45.71(\mathrm{SD}=5.1)$ points post-remediation $(95 \% \mathrm{CI}=-14.52$ to $-9.83 ; \mathrm{p}<0.001 ; \mathrm{r}=0.77)$. The students indicated that they were better equipped (post-remediation) to obtain required information from patients, monitor their diagnostic thinking and acquire the required knowledge and skills to succeed.

Research Question 2: What interventions are perceived to be most useful?

Independent-samples t-test revealed that there were no significant group differences in relation to preferred remediation activities. Although not significant, it was noted that the $5^{\text {th }}$ year students considered the presentation skills more worthwhile than the $4^{\text {th }}$ year students; a similar trend was observed between the international and domestic students with higher ratings from the international students.

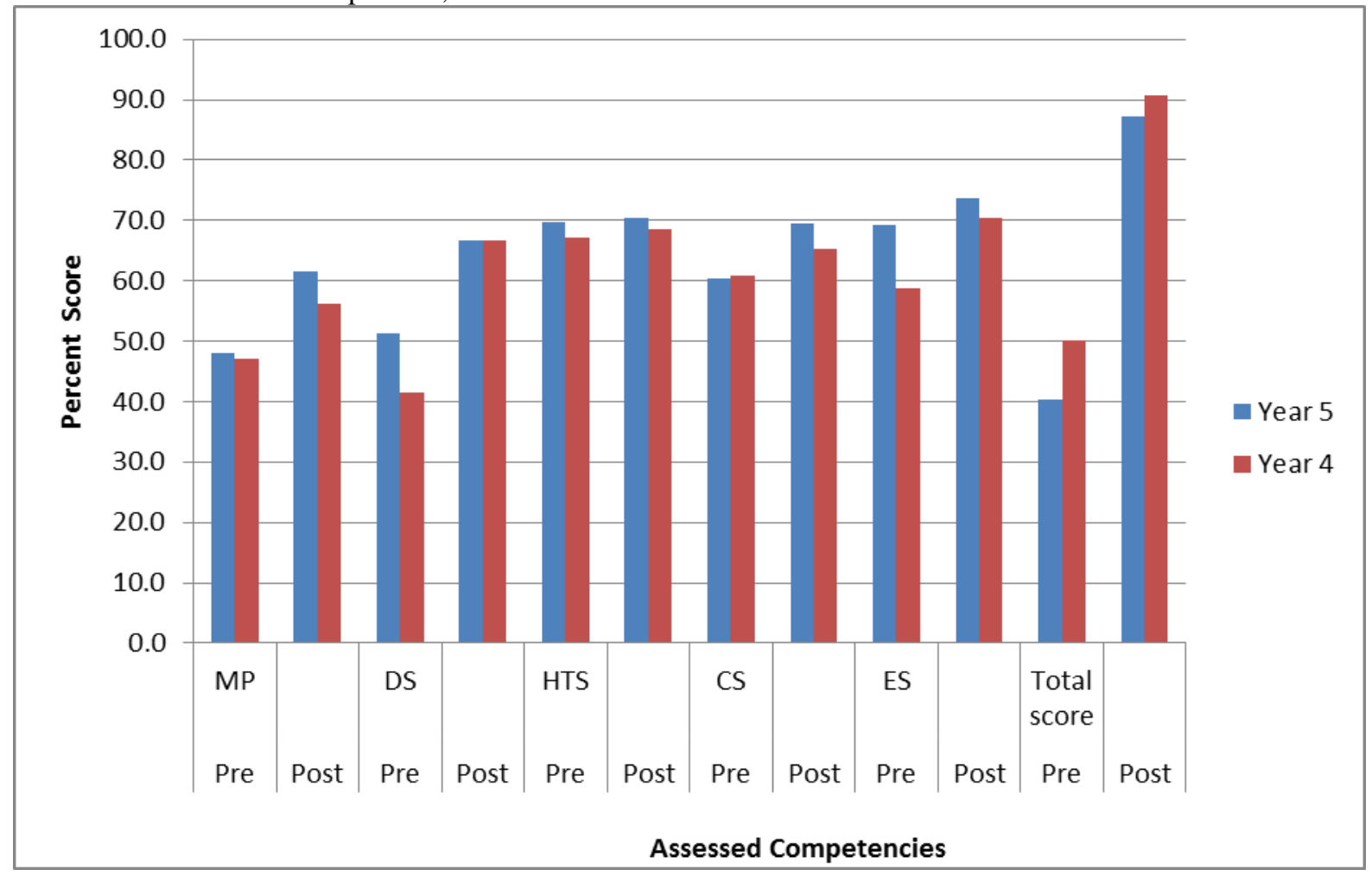

Figure 1. Student performance on OSCE pre and post -remediation program 
Table 2. Comparison of perceived SE means scores pre and post remediation program (n=17)

\begin{tabular}{|c|c|c|c|c|c|c|}
\hline & & & $\begin{array}{r}9 \\
\text { Conf } \\
\text { Interv }\end{array}$ & $\begin{array}{l}\% \\
\text { lence } \\
\text { ( (CI) }\end{array}$ & & \\
\hline Item & $\begin{array}{c}\text { Pre- } \\
\text { remediation } \\
\text { program } \\
\text { (SD) }\end{array}$ & $\begin{array}{l}\text { Post- } \\
\text { remediation } \\
\text { program } \\
\text { (SD) }\end{array}$ & Lower & Upper & $\begin{array}{c}\text { Mean } \\
\text { Difference }\end{array}$ & $\begin{array}{c}\text { Effect } \\
\text { Size } \\
\text { (r) }\end{array}$ \\
\hline I have the ability to gain the knowledge I need to succeed this year & $3.41(0.50)$ & $4.35(0.70)$ & -1.27 & -0.60 & $-0.94^{\ddagger}$ & 0.61 \\
\hline I have the ability to acquire the skills I need to succeed this year & $3.11(0.49)$ & $4.29(0.69)$ & -1.50 & -0.84 & $-1.18^{\ddagger}$ & 0.70 \\
\hline I am confident in approaching patients during my clinical placements & $3.00(1.00)$ & $4.29(0.58)$ & -1.69 & -0.89 & $-1.29^{\ddagger}$ & 0.62 \\
\hline I am comfortable with asking my clinical supervisors questions & $3.05(0.96)$ & $4.12(0.69)$ & -1.72 & -0.39 & $-1.06^{\ddagger}$ & 0.54 \\
\hline I can explain medical information to patients & $2.94(0.75)$ & $4.12(0.60)$ & -1.59 & -0.76 & $-1.17^{\ddagger}$ & 0.66 \\
\hline I am able to get the information I need from patients & $2.94(0.75)$ & $4.29(0.59)$ & -1.75 & -0.94 & $-1.35^{\ddagger}$ & 0.71 \\
\hline I am comfortable with discussing emotional topics with patients & $2.71(0.77)$ & $3.82(0.95)$ & -1.51 & -0.71 & $-1.12^{\ddagger}$ & 0.54 \\
\hline $\begin{array}{l}\text { I have the skills to help me deal with most stressful situations I } \\
\text { encounter }\end{array}$ & $2.88(0.69)$ & $3.94(0.83)$ & -1.48 & -0.63 & $-1.06^{\ddagger}$ & 0.57 \\
\hline I feel comfortable asking for help if I need it & $2.76(0.75)$ & $4.05(0.83)$ & -1.73 & -0.85 & $-1.29^{\ddagger}$ & 0.63 \\
\hline I can make a differential diagnosis from available information & $3.47(0.51)$ & $4.12(0.60)$ & -0.90 & -0.39 & $-0.65^{\ddagger}$ & 0.50 \\
\hline $\begin{array}{c}\text { I feel able to monitor my diagnostic thinking and make adjustments } \\
\text { during a patient interview }\end{array}$ & $3.24(0.75)$ & $4.29(0.59)$ & -1.61 & -0.49 & $-1.06^{\ddagger}$ & 0.61 \\
\hline Total scores & $\begin{array}{l}33.53 \\
(4.98)\end{array}$ & $\begin{array}{l}45.71 \\
(5.13)\end{array}$ & -14.52 & -9.83 & $-12.18^{\ddagger}$ & 0.77 \\
\hline
\end{tabular}

$\ddagger \mathrm{P}<0.001$

\subsection{Qualitative}

Research Question 3: What are the perceived longterm benefits of the intervention program on the clinical performance of underperforming medical students?

Findings from the qualitative data were categorised into three major themes (Self-efficacy beliefs, Supportive learning environment and Development of required skills) with eight subthemes as described below and presented with verbatim illustrative quotes from the written responses (WR), 2011 interviews (Ia) and the 2012 interviews (Ib) (Table 3).

The participants indicated that the most beneficial part of the intervention was that it afforded them enhanced self-efficacy beliefs and this was achieved through a supportive learning environment and the development of essential skills. They indicated that the presentation skills, bedside tutorials and the peer-learning sessions were the most useful intervention activities. On the whole, the participants felt the program had helped them to improve their clinical reasoning and communication skills and more importantly, it had increased their confidence that they could succeed in their studies and engaged them in deep learning which allowed them to embrace the concept of lifelong learning.

\subsubsection{Self-Efficacy}

\subsubsection{Self-Growth}

Participants indicated that the program assisted them in rediscovering themselves and enabled self-growth. It also gave them the opportunity to extend themselves and allowed them to rise above personal embarrassment.

"The self-growth was what made it work, that internal struggle, what have I done wrong? What's wrong with me? An internal struggle. The fight within you to change, I am going to use that internal strength to want to do well" (Ib).
"The people who would do well in the program are those who are self-motivated and really want to listen to critique and really understand it and want to do well" (Ib).

They also stated how failure in their previous exams had lowered their self-confidence but with the remediation program, they were able to see their confidence grow.

"It was depressing at the start of the year" (Ia)

"After the support this year, I feel more confident. My confidence grows with the program. Each time my confidence grows a little and I try new things and it grows more and it helps me to deal with things on the ward. If I don't volunteer there, I don't learn, so the confidence to put myself forward is most important to my learning" (Ia).

"It was nice to be ok this year. Just really carrying through the whole year, I think the results of the year before helped. Making sure, knowing I was on a good run" (Ib)

\subsubsection{Insight Into (Acknowledgment of) Skill Deficits}

The program enabled the participants to acknowledge that they needed support. It also helped them to gain insight into their areas of weaknesses and how to tackle their problems.

"I think the turning point in 2011 was when I got an email from faculty. I felt I needed support and felt that I was being supported by the school. Helpful to understand and identify areas that need to be improved" (Ib).

\subsubsection{Orientation to the Big Picture}

The program aided the participants in reassessing their reasons for choosing to study medicine. It also reaffirmed their value as potential doctors and the belief that they will be capable future doctors and people of value.

"I think I was always motivated. Lots of us want to do medicine and are motivated on different levels and that's why we put ourselves through this pain, but the energy in the stages when I was struggling, that was my downfall, made me so anxious about doing well. The reward wasn't 
there, and it might have shown as not being interested" (Ib).

"I think struggling students need that reward, a reminder of why they are here They haven't been reinforced that they are doing well and they might feel that they are not good enough and if they have Michael's class and small simulations, they can succeed and slowly build their confidence up and they can look and feel more motivated". "Intrinsic reward in helping people and being acknowledged as a person of value" (Ib).

"You need those ah ha moments, and you thank those moments later....even though you were suffering at the time and it was a terrible moment. The thing that hits home, that is the growth that happened" (Ib).

\subsubsection{Supportive Learning Environment}

\subsubsection{Novel Teaching Methods}

The participants indicated that they were quite reluctant to participate in the program at first, especially the presentation skills sessions, because they felt these were unrelated to core medical knowledge. However, on reflection, the presentation skills session was rated as the most useful part of the program for them.

"The sessions were something I had to do, but they weren't clinical or medicine related. Scary at first, they were brand new and I didn't know what to expect. Then they were fun and enjoyable" (Ia).

"It was great. Something you would not imagine yourself doing in Medicine. I remember him talking about breathing when you are nervous. And to speak up, to speak up loudly when you are in an exam situation if you are a bit nervous" (Ib).

They also indicated that the mock OSCE with junior students gave them the opportunity to reflect on expected standards from the examiner's point of view. The teaching process also promoted deep learning and boosted their confidence.

"And you realise that you are trying to help the students when you are part of a simulation as an examiner or role player and that must be how the real examiners feel on the day".

"It forces you to learn something really well in order to teach it and it's a confidence boost and you have gained knowledge and skills to impart to others and they appreciate your time and effort” (Ib).

\subsubsection{Teachers as Exemplars}

Participants emphasised the importance of quality teaching as this provided the opportunity to "learn to think like a doctor”. The participants also appreciated the efforts and commitment that the teachers put into supporting them to succeed.

"The main issue I had was integrating what I had learnt from the earlier years in to something useful across the curriculum; that was the challenge for me in the final year. This is where the sessions were so good. in the beginning firstly you start to work out what their thought process was, what is it they are thinking and then you try out that thought process yourself and then compare it with what the clinician is explaining. It is a good session to learn how to practice clinical reasoning. The two clinicians we had ...they explain their thought process in a more direct way and how they came up with the conclusions... thinking this, this and this" (Ib).

\subsubsection{Support from Clinicians, Mentors and Peers}

Participants indicated that they received academic and moral support from their teachers and peers. The program created a supportive learning environment with peers in similar situation.

"Personally, talking to people who have experienced failure in the past and try not to repeat their mistakes was helpful" (Ia)

"It allowed me to get closer to others in the group and to bond with them. People who were in the remediation group with similar struggles, so it made me feel that I wasn't alone and just having fun together. An opportunity to bond and we didn't feel like strugglers in that program. It was really fun" (Ib).

The honest and constructive feedbacks provided by the teachers were also seen as enablers in the remediation journey.

"High quality feedback, sessions were very good because they were one on one. He would ask me to go and see a patient and present to him, so he put me on the spot. I feel that those kinds of situations which put you on the spot do help you" (Ia).

"He is a very good mentor and I learnt a lot from him and not just from the medical side but professional learning eg writing extra detail on the form" (Ib).

\subsubsection{Development of Required Skills}

\subsubsection{Adaptability to New Learning Styles}

Although cultural adjustment had been very challenging for the international students, the participants indicated that the nature of the profession required impromptu thinking and adaptability to different situations and learning styles.

"Last year it forced me to adapt in order to pass the OSCE, each time I practised and applied different ways of approaching the OSCE. Michael's classes, forced me to adapt and respond on the go, no time to prepare and so that was valuable, gave some practice in adapting in various unusual situations.” (Ib).

\subsubsection{Verbal and Non-Verbal Communication}

Most of the international students indicated that their biggest problem was communication and they felt that the program gave them an opportunity to experiment with communication in a safe environment. They were also able to understand the importance of body language. All the participants felt that the presentation skills session provided them with much needed generic communication skills that were useful in stressful situations.

"He actually pointed out my communication weakness and that was helpful, not so much for OSCE. But the breathing techniques did help with OSCE, to relax and the tongue twisters, it actually helped to articulate the words. During the course he was helping us to project our voice and our opinion, he stressed on that".

"Definitely the presentation skills session was the most helpful... mainly on the communication skills. If done earlier in fourth year, would have been valuable. It would really help international students". 
"I learnt a little about the body language, coming from a country where we don't tend to express ourselves and which is more conservative. In my home country most of the doctors are quite stoic. Working on the nuance of body language was important" (Ib).

Participants suggested that the remediation program should be introduced earlier in the course, to improve clinical performance and bridge English language barriers - “...perhaps rolling out this program in earlier years, thereby improving the knowledge of diagnosis, investigation and overall management in the clinical setting “(WR).

"for international students who need remediation, language can be a big barrier in passing OSCE, thus more sessions on this would be good" (WR).

However, they indicated that some of the clinician led OSCE practice sessions were repetitive.

"some of the sessions with the clinicians were quite repetitive so it would look like it was not as useful as the other sessions" (WR).

Table 3. Emerging Themes from the written responses and interviews

\begin{tabular}{|c|c|}
\hline Theme & Sample Quotes \\
\hline Self-Efficacy & $\begin{array}{l}\text { "Those sessions improved my confidence in talking to patients and senior colleagues” (WR) } \\
\text { "The presentation skills helped to reduce stress and increase confidence” (WR) } \\
\text { "I built trust from the senior doctors by showing that I could do things, now I see myself as a doctor, I can see now what I couldn't } \\
\text { see last year" (WR) } \\
\text { "It's not so much that I have changed in myself over the time. I have become my old self since this intervention. I was another } \\
\text { person when things weren’t going well” (Ia) } \\
\text { "Confident that I can continue this path and be a confident doctor” (Ib) } \\
\text { "What really hit me was that moment when we had OSCE simulations and it was videotaped so that we could go back and assess } \\
\text { it. When we came to assessing that, Michael was really harsh because he really believed in me. It really devastated me at that time } \\
\text { and made me go back to drawing board and look at what I was doing in OSCEs, what was happening. I was obviously showing } \\
\text { good progress in the program, but when it came to OSCEs I was nervous, I was not believing in my abilities and I thought what } \\
\text { can I do to improve, believe in myself and show more confidence and I ran with that thought and I practiced in front of video } \\
\text { cameras at home and really worked on it and I watched it with my friend and he gave me a few pointers on how to improve from } \\
\text { the verbal and non- verbal point of view in the OSCEs and I was just constantly practicing at home with friends, friends I trust. I } \\
\text { think that helped. I think that was a really pivotal moment, the moment I got lots of critique in that room”(Ib) } \\
\text { "It was nice to be ok this year. Just really carrying through the whole year, I think the results of the year before helped. Making } \\
\text { sure, knowing I was on a good run”(Ib) }\end{array}$ \\
\hline $\begin{array}{l}\text { Supportive } \\
\text { Learning } \\
\text { Environment }\end{array}$ & $\begin{array}{l}\text { "The presentation skills coordinator provided good, honest feedback on speaking and presenting; also helped learn how to manage } \\
\text { stressful environment by stressing the students out during the sessions in a controlled way" (WR) } \\
\text { "The OSCE practice sessions and bedside teaching with clinicians, they provided good feedback" (Ia) } \\
\text { "I also liked the mock OSCE; it made me comfortable for the actual OSCE". I enjoyed the speech therapy sessions, they helped } \\
\text { improve my confidence” (WR) } \\
\text { "In hindsight, being videotaped was helpful in identifying weaknesses in communication skills" (WR) } \\
\text { "Knowing that there was support early on, rather than when it was at a stage when it would be difficult to catch up" (WR) } \\
\text { "The most helpful thing for me was peer teaching, I felt comfortable to ask dumb questions, it's easier than asking a teacher you } \\
\text { don’t feel humiliated if you get it wrong” (Ia) } \\
\text { "Michael is right in your face and he forces you to think about why you have been doing things the way you have been doing it. } \\
\text { Michael's sessions made you more expressive when you come from our country"(Ib) }\end{array}$ \\
\hline $\begin{array}{c}\text { Development } \\
\text { of Required } \\
\text { Skills }\end{array}$ & $\begin{array}{l}\text { "I now know how to adapt to Aussie words, to speak more clearly and to slow down to a slower pace... this was a boost to my } \\
\text { confidence" (Ia) } \\
\text { "Now I remember in clinic to speak and to give the patient time to respond and to ask questions, it's the art of listening” (Ia) } \\
\text { "Counselling was not really helpful.... lack of insight is one problem. People don't see they need help, they are just in survival } \\
\text { mode" (Ia) } \\
\text { "Tips on how to relax heightened my awareness, keeping shoulders down etc. " (Ia) } \\
\text { "(They).... helped mostly by putting you on the spot and making you do it. It creates more anxiety at the start, but helps in the long } \\
\text { run, gives you the thought that you have done this before and can do it again" (WR) } \\
\text { "I remember him talking about breathing when you are nervous. And to speak up, to speak up loudly when you are in an exam } \\
\text { situation if you are a bit nervous"(Ib) } \\
\text { "Getting used to the culture was the big thing; I had never lived in another country; that took some getting used to Aussie slang. } \\
\text { Taking histories, I was worried about the conversations, back at home, we had to do that as well, but here you just wonder how the } \\
\text { patient will respond to your questions" (Ib) }\end{array}$ \\
\hline
\end{tabular}

\section{Discussion}

The findings from this study have highlighted the importance of SE beliefs in motivating underperforming medical students and improving their clinical performance. With regards to the first research question, the remarkable and sustained improvement in OSCE performance after the remediation program confirms that our intervention program consisting of multiple, cost effective, group learning activities aimed at building SE was effective. This confirms that "SE is a critical determinant of the selfregulatory practices in which individuals engage as they go about the important task of self-correcting their actions and cognitions" [41]. Our result underscores the findings of Winston et al., [13] who reported a 64\% increased pass rate after implementing a cognitive skills intervention program.
Consistent with other studies [5], our pre-intervention analysis supports the view that deficiencies in both academic/cognitive and non-academic/affective skills, can contribute to underperformance. Communication problems are frequently seen as the cause of underperformance [5] but this only applied to international students in our study, corroborating the work of MalauAduli [42]. For domestic students, the problem appears to be more related to poor clinical reasoning and developing management plans. Despite the differences in the underlying reasons for underperformance, both groups were significantly affected by the pre-intervention failure outcome. This may indicate that although there might be cultural differences in causal factors for underperformance, there seems to be no cultural difference in response to SE beliefs. Being designated as an underperforming student in a high status degree such as medicine, of itself damages self-confidence in these previously successful students and 
leads to anxiety. Anxiety can be interpreted as incompetence by students and of itself feeds failure $[43,44]$.

In relation to our second research question, although there were no statistically significant group differences in participants' preferences for the remediation activities, it was observed that the students (particularly $5^{\text {th }}$ year) benefitted the most from the presentation skills sessions. Our qualitative findings indicated that a reason for this benefit may have been that the participants were encouraged to believe in themselves and at the same time, challenged and extended beyond their comfort zones especially during these sessions. Winston et al. [14] extoll the "the nurturing mentor" as teacher, whilst underlining that to explicitly define progress requirements, it is essential to "critique candidly". The participants stated that it was the wide range of activities which fed into a growing sense of confidence in their ability to succeed. Such programs "help to create an empowering awareness of previously unimagined capacities” [45].

The participants' perceived improvements in selfconfidence, SE beliefs and the actual improved clinical performance, which were reported/observed in 2012 (one year after the intervention), provide answers to our third research question. SE influences the degree of skill acquisition and retention in learning situations [15]; hence the improved self-confidence and academic performance post remediation intervention. In addition, these activities were offered early in the year and regularly. This is in contrast to the usual short term remediation offered post OSCE failure for 6-8 weeks, which may feed into short term, rather than sustained results [9]. According to Pell et al [12], "weak students may need additional time to consolidate existing learning”. There were some indicators in our study that learning methods had changed for the longer term and beneficial not only in OSCE performance but for life long, reflective learning.

Studies in educational fields other than medicine have demonstrated that interventions augmenting domainspecific SE produce wide ranging benefits, including participants' power as agents to affect self-change $[17,28]$. The remediation activities utilised in our program provided the participants with the opportunity to better understand the complexity of the clinical environment and expected performances. These academic outcomes were achieved through the use of standard effective educational dimensions including mastery, modelling, persuasion and feedback to increase the students' perceived capabilities, which is a precursor of academic SE judgements [28].

Our study reaffirms some of the key elements of an effective intervention strategy found in the literature including: having good quality teaching [46], a strategic approach including using a specific educational theory [3], individual analysis of performance and feedback [47] together with enough Faculty resources [9]. Elements we did not find as important as other studies included: treating learners as a heterogeneous group and tailor making intervention for each student [10], or delivering a program focusing just on OSCE performance [3,11].

The limitations of this study include the lack of a control group, and lack of a longer-term follow up. In addition, the small sample size and the use of data from one medical school imply that the findings of this study should be cautiously applied to other settings. However, the triangulation of data in this study provides a confirmation of our findings through the convergence of the different perspectives. Further studies using similar intervention strategies will be required to explore if our findings are reproducible in other settings

\section{Conclusions}

This study has demonstrated the utility of a multiactivity intervention that promoted self-efficacy to improve academic achievement and clinical performance in underperforming medical students. This approach contains a strong activist dimension, which not only seeks to understand reasons for failure, but also through motivation, modelling, persuasion and feedback bring about positive transformation in learning ability in the short and medium term.

\section{Acknowledgement}

The authors acknowledge Michael Beresford, Anne Rothwell, Morag Porteous, Andrew Black and David Langsford for teaching into the ALSO program. The authors also thank the students who participated in the remediation program and Gail Richardson for processing the questionnaires. Special thanks to Phil Patman for statistical support.

\section{References}

[1] Yates J, James D. Predicting the "strugglers": A case-control study of students at Nottingham University Medical School. British Medical Journal. 2006;332:1009-1013.

[2] Faustinella F, Orlando PR, Colletti LA, Juneja HS, Perkowski LC. Remediation strategies and students' clinical performance. Medical Teacher. 2004;26:664-665.

[3] White C, Ross P, Gruppen L. Remediating student's failed OSCE performances at one school: the effects of self-assessment, reflection and feedback. Academic Medicine. 2009;84: 651-654

[4] Hauer KE, Teherani A, Kerr KM, O’Sullivan PS, Irby DM. Student performance problems in medical school clinical skills assessments. Academic Medicine. 2007;82 (supplement) S: 69-72.

[5] Sayer M, Chaput De Saintonge M, Evans D, Wood D. Support for students with academic difficulties. Medical Education. 2002;36:643-650.

[6] Beckert L, Wilkinson TJ, Sainsbury R. A needs-based study and examination skills course improves students' performance. Medical Education. 2003; 37:424-428.

[7] Chou CL, Chang A, Hauer KE. Remediation workshop for medical students in patient-doctor interaction skills. Medical Education. 2008;42:537.

[8] Klamen DL, Williams RG. The efficacy of a targeted remediation process for students who fail standardised patient examinations. Teaching and Learning in Medicine. 2011;23: 3-11

[9] Hauer KE, Ciccone A, Henzel TR, Katsufrakis P, Miller SH, Norcross WA, Papdakis MA, Irby DM. Remediation of the deficiencies of physicians across the continuum from medical school to practice: A thematic review of the literature. Academic Medicine. 2009;84(12):1822-1832.

[10] Cleland J, Leggett H, Sandars J, Costa MJ, Patel R, Moffat,M. The remediation challenge: theoretical and methodological insights from a systematic review. Medicine Education. 2013;47:242-251.

[11] Cleland J, Mackenzie RK, Ross S, Sinclair HK, Lee AJ. A remedial intervention linked to a formative assessment is effective in terms of improving student performance in subsequent degree examinations. Medical Teacher. 2010;32:e185-190.

[12] Pell G, Fuller R, Homer M, Roberts T. Is short-term remediation after OSCE failure sustained? A retrospective analysis of the 
longitudinal attainment of underperforming students in OSCE assessments. Medical Teacher. 2012;34:146-150.

[13] Winston KA, van der Vleuten CPM, Scherpbier AJJA. An investigation into the design and effectiveness of a mandatory cognitive skills programme for at-risk medical students. Medical Teacher 2010;32 (3):236-43.

[14] Winston KA, van der Vleuten CPM, Scherpbier AJJA. At-risk medical students: implications of students' voice for the theory and practice of remediation. Medical Education. 2010: 44:10381047.

[15] Bandura A. Social Foundations of thought and action: A social cognitive theory. Englewood Cliffs NJ Prentice-Hall Inc 1986.

[16] Gist ME, Schwoerer C, Rosen B. Effects of alternative training methods on self-efficacy and performance in computer software training. Journal of Applied Psychology. 1989;74:884-891.

[17] Zimmerman BJ. Attaining self-regulation: A social cognitive perspective. In: Boekaerts, M., Pintrich, P. R., and Zeidner, M. (eds.), Handbook of Self-Regulation, JAI. Press, New York, 2000; pp. 13-39.

[18] Pololi LH, Potter S. Behavioural change in preventive medicine: An efficacy assessment of a physician education module. Journal of General Internal Medicine, 1996;11:545-547.

[19] Bower DJ, Wolkomir MS, Schubot DB. The effects of the ALSO course as an educational intervention for residents. Family Medicine. 1997;28:187-193.

[20] Lorenz RA, Gregory RO, Davis DL. Utility of a brief self-efficacy scale in clinical training program evaluation. Evaluation and the Health Professions. 2000;23:182-192.

[21] Bruning RH, Schraw GJ, Ronning RR. Cognitive psychology and instruction. Upper Saddle River, NJ: Merrill, 1999.

[22] Cleary TJ, Zimmerman BJ. Self-regulation differences during athletic practice by experts, non-experts, and novices. Journal of Applied Sport Psychology. 2010;13:185-206.

[23] Sandars J, Cleary TJ. Self-regulation theory: applications to medical education: AMEE Guide No. 58. Medical Teach.er 2011;33(11):875-886.

[24] Zimmerman BJ. Investigations self-regulation and motivation: historical background, methodological developments and future prospects. American Educational Research Journal. 2008;45(1):166-183.

[25] Weinstein CE, Husman J, Dierking DR. Self-regulation interventions with a focus on learning strategies. In: Boekaerts, M., Pintrich, P. R., and Zeidner, M. (eds.), Handbook of SelfRegulation, JAI. Press, New York, 2000; pp. 727-747.

[26] Zimmerman BJ, Bonner S, Kovach R. Developing self-regulated learners: Beyond achievement to self-efficacy. Washington, DC: American Psychological Association, 1996.

[27] Schunk DH., Ertmer PA. Self-regulation and academic learning: self-efficacy enhancing interventions. In: Boekaerts, M., Pintrich, P. R., and Zeidner, M. (eds.), Handbook of Self-Regulation, JAI. Press, New York, 2000; pp. 631-649.

[28] Bandura A. Self-efficacy: Toward a unifying theory of behaviour change. Psychological Review. 1977;84:191-215.
[29] Locke EA, Frederick E, Lee C, Bobko P. Effect of self-efficacy, goals, and task strategies on task performance. Journal of Applied Psychology. 1984;69:241-2.

[30] Wood RE, Bandura A. Impact of conceptions of ability on selfregulatory mechanisms and complex decision making. Journal of Personality and Social Psychology. 1989;56:407-415.

[31] Chemers M, Hu L, Garcia B. Academic self-efficacy and first year college student performance and adjustment. Journal of Educational Psychology. 2001;93:55-64.

[32] Mavis B. Self-Efficacy and OSCE Performance Among Second Year Medical Students Advances in Health Sciences Education. 2001;6: 93-102.

[33] Allen R, Heard J, Savidge M, Bitterqle J, Cantrell M, Huffmaster T. Surveying students' attitudes during the OSCE. Advances in Health Sciences Education. 1998;3:197-206.

[34] Schifferdecker KE, Reed VA. Using mixed-methods research in medical education: Basic guidelines for researchers. Medical Education. 2009;43:637-644.

[35] Skeff KM, Stratos GA, Bergen MR. Evaluation of a medical faculty development program: a comparison of traditional pre/post and retrospective pre/post self-assessment ratings. Evaluation of the Health Professions. 1992;15:350-366.

[36] Hewson MG, Copeland HL, Fishleder AJ. What's the use of faculty development? Program evaluation using retrospective selfassessments and independent performance ratings. Teaching and Learning in Medicine. 2001;13:153-160.

[37] SPSS Inc. IBM SPSS Statistics 19.0 for Windows User's Guide. SPSS Inc. Chicago IL.

[38] Braun V, Clarke V. Using thematic analysis in psychology. Qualitative Research in Psychology. 2006;3(2):77-101.

[39] Frith H, Gleeson K. Clothing and embodiment: men managing body image and appearance. Psychology of Men \& Masculinity. 2004;5(1):40-48.

[40] Boyatzis RE. Transforming qualitative information: thematic analysis and code development, Sage, 1998.

[41] Pajares F. Self-efficacy theory. [Internet, cited 2013 March 12] Available from http://www.education.com/reference/article/selfefficacy-theory/.

[42] Malau-Aduli BS. Exploring the experiences and coping strategies of international medical students. BMC Medical Education 2011;11:40.

[43] Tooth D, Tonge K, McManus IC. Anxiety and study methods in preclinical students: causal relation to academic performance. Medical Education 1989;23:416-21.

[44] Usher EL, Pajares F. Self-efficacy for self-regulated learning: A validation study. Educational and Psychological Measurement. 2008;68:443-463.

[45] Nillsen R. Can the love of learning be taught? Journal of University Teaching and Learning Practice. 2004;1(1):1-9.

[46] Winston KA, van der Vleuten CPM, Scherpbier AJJA. The role of the teacher in remediating at-risk medical students. Medical Teacher. 2012;34:e732-734.

[47] Sinclair HK, Cleland JA. Undergraduate medical students: who seeks formative feedback? Medical Education. 2007;41:580-582. 